\title{
Mobile Apps in Daily Learning Activities
}

\author{
https://doi.org/10.3991/ijim.v12i6.9659 \\ Ivo Damyanov( $\left.{ }^{\bowtie}\right)$, Nikolay Tsankov \\ South-West University, Blagoevgrad, Bulgaria \\ damianoveswu.bg
}

\begin{abstract}
The use of mobile devices is increasing in daily learning activities, providing single-person use combined with interactive learning materials, simulations, voice recognition and educational games. Mobile app stores bring to learners a large amount of mobile applications, but their value and effectiveness to support these learning activities is far from being adequately studied.

In this paper, we present our recent study related to the opportunities for smart devices to be used in school education, outlining the main obstacles and challenges. The subject of the research is students' interest in the use of multimedia mobile devices for educational purposes. The aim of the study is to establish the main determinants for the complete and purposeful application of smart devices in school education.
\end{abstract}

Keywords—-mobile apps, smart devices, learning activities, mobile supported education

\section{Introduction}

The popularity of mobile devices has been rapidly changing learning, communicating, even our very life styles. The use of mobile technologies remarkably extends learning opportunities, needs, goals, and has a profound effect on many learning activities and learning styles [1].

The existing education system and the widely used learning methods in the learning process can hardly hold the attention of students who are accustomed to the use of digital sources of information and entertainment. Digital students are put in a situation where they act as consumers of certain learning content and they expect to manage the virtual environment themselves and interact with it on their own. Experience shows that there is a fundamental discrepancy between the way children think, communicate and learn, and how the school interacts with them. To modern students "inhabiting virtual realities is much more than a new kind of pastime. Rather, it sets up a mode of perceiving and interacting with the world around in which the resolution of a dilemma, the overcoming of a difficulty, the discovery of something new, important or necessary is a matter of a single click of the mouse or just a touch of the screen" [2]. Digital children are born in a different world, live at different speeds, their brains function differently, and it is impossible to adapt to the education system, as it exists. The only solution is to adapt the education system to them [3]. 
The use of information and communication technologies is an integral part of the modern education. The knowledge acquired through new technologies also develops other personal skills that later promote life integration in society. Modern adolescents live in a highly interactive environment, communicate, and acquire knowledge and skills in a digital world using different technological means. Through their actions, they take on different roles-not only as passive users of resources but also as active artists and creators. The resources used for technological support for learning, which are more widespread in schools, are many and varied, and their functionality is complemented and built on by appropriate software tools: electronic textbooks, platforms for creating, publishing, storing, searching for and sharing electronic learning resources, systems for organizing and managing the learning process, etc. Supporting the learning process also includes opportunities to provide content and audio and video resources through Internet technologies-social networks, blogs, sites, and more. In their skillful and expedient use, new methods of training are being developed, traditional ones are improved, a wider variety of pedagogical situations are being developed [4].

The Digital Agenda of Europe ${ }^{1}$ is linked to the initiative to overcome the lack of information and communication skills, as one of the most important obstacles to master the potential of new technologies by enhancing digital literacy and skills upgrading, by encouraging the formation of long-lasting e-skills and the introduction of digital literacy policies. According to the report, information and communication technologies (ICT) provide a variety of methods and tools that reveal new opportunities in the classroom and beyond. They definitely help to support the learning process by organizing it in a way that takes into account individual learners' needs, and enable them to build up important digital competencies that are needed for our knowledge-based economy.

Mobile learning is a new dimension and an opportunity for a quality change in the educational process. It is undoubtedly related to the search for ways to increase the motivation and interest of learners and the individualization and personalization of learning in the spirit of applying the constructivist and connectivist approach to the learning. Investments in mobile learning are related to the formation and development of digital competence and trace the readiness for systematic and targeted use of mobile technologies for lifelong learning.

With the continuous increment of the computation power of handheld computers, enrichment with sensors and the high speed connectivity to the Internet-mobile devices provide single-person use, online access to interactive learning materials, simulations, capabilities for voice and image recognition and rich educational games. Google Play and App Store bring to learners a large amount of mobile applications, but their value and effectiveness to support these learning activities requires serious exploration.

In this paper, we present our empirical study conducted between April and June 2018 with pupils aged between 14 and 18 on students' interest in the use of multimedia mobile devices for educational purposes.

\footnotetext{
${ }^{1}$ Key Data on Learning and Innovation through ICT at School in Europe 2011, http://eacea.ec.europa.eu/education/eurydice/
} 


\section{$2 \quad$ Literature Review}

El-Hussein and Cronje in [5] briefly define the concept of mobility in three significant areas: mobility of technology, mobility of learning, and mobility of learner. Mobility of technology encompasses smartphones, tablets, Personal Digital Assistants (PDAs). Mobile devices used to deliver higher education content and instruction can also function as audioplayers, media-players and digital cameras and they are furnished with mobile data and WiFi connectivity. Mobility of learning also generates new modes of educational delivery: personalized, learner-centered, situated, collaborative, ubiquitous, and lifelong learning [6]. With mobile learning, learning can occurs at any place and at any time-thus we can speak for mobility of learners.

\subsection{Key Opportunities in Mobile Learning}

In spite of the existing technological limitations, such as differences in the parameters and technological capacities of mobile devices, and the lack of uniform standards for the design of mobile learning resources, innovative examples of mobile learning are popping up worldwide. Mobile learning establishes favorable conditions for: (1) creating a personal learning space; (2) a full learning organization through quick access to Internet resources; (3) optimization of group and team educational communication and activities with the targeted use of cloud technologies; (4) opportunities to use augmented and mixed reality and gaming educational technologies; (5) complete diagnostics and assessment of learners' performance by customizing the requirements and responsibilities for learning; (6) use of rich set of additional technological solutions for educational purposes.

Educators and developers should focus their resources to improve mobile learning [7] by (1) encouraging "anywhere, anytime" learning; (2) reach underserved children; (3) improve $21^{\text {st }}$ century social integrations; (4) fit with learning environments and (5) enable a personalized learning experience.

Mobility training by mobile phones and PDAs creates opportunities for the so-called ubiquitous learning environments that encourage learning conditions to be around learners, even if they are not always aware of it, that is, to organize their own digital environments.

New developments in mobile technology are rapidly widening the scope of learning in areas outside formal education (i.e., informal learning) by allowing flexible and instant access to rich digital resources. Mobile learning (or m-learning) can also play a significant supplemental role within formal education. The potential benefits of $\mathrm{m}$ learning have been widely touted from a range of purposes, including cost savings, ubiquitous communications, study aids, and location-based services [8].

As a constructive perspective to the dilemmas in education and the classroom system, Y. Rasheva-Merdzhanova [9] points out open education, open school environment, open learning, open learning content, open methods, open learning environment, open evaluation. According to the author, open learning synergy environment is distinguished by: (1) balance in the learning areas-classroom/external social space (time and 
spatial planning), (2) agreed coordination and distribution of the functions teacher-student in the process of pedagogical interaction (time and spatial planning), (3) assessed co-ordinated participation of teachers and students as social partners (time and spatial planning).

Analyzing pedagogical concepts in the context of the peculiarities of the $21^{\text {st }}$ century pedagogy, Georgieva-Lazarova and L. Lazarov [10] characterize the digital educational environment as an opportunity to create personal freedom for every trainee who can learn at a convenient time and using the most appropriate personal style of learning where the role of the teacher is to influence the use of this freedom by offering different ways of transferring knowledge and learning styles. In other words, this is a wellthought-out process that is offered to students, relying on their motivation and engagement.

By education in a digital environment Lazarova [11] understands training in which the digital educational environment is used to: (1) preserve and provide additional learning resources serving as a support function in the traditional form of learning, and (2) provide pupils with opportunities to form or participate in small learning groups, as one of the strongest determinants of their success. This definition focuses primarily on the possibilities of integrating learning into digital environments and traditional learning as complementary in the context of blended learning. But in essence, learning in a digital environment far outweighs its support function in traditional learning and cooperative learning. Learning in a digital environment is essentially multisensory training.

Multisensory training is training aimed at forming and enhancing pupils' ability to simultaneously process, transform and use information from their various sensory systems in the process of learning and problem solving by organizing learning content and didactic environment on a multisensory principle with resulting formation of multisensory competence and development of meta-thinking (cognitive-affective) and behavioral strategies [12].

The evolution of learning is a movement of unconditionalness as directions of influence, differentiation of functions and activities between teacher and pupils to conditionality-and that is not just the transferability or transfer of functions and individual activities, but their organic mixing, synergy. In this "conditional learning" the student is also a teacher (and not only from time to time) and the teacher is also a student (constantly). In this conditional learning, the effects are on training and development on both types of subjects who own and cease to be gradually two different specific subjects, and start to have more and more common characteristics [12].

\subsection{Key Challenges in Mobile Learning}

Along with the potential of mobile learning to build and support creative, collaborative and communicative learning environment, it comes with certain challenges that must be addressed. One can classify this challenges in [13] five types-management and institutional challenges, design challenges, technical challenges, evaluation challenges and cultural and social challenges. 
Management and institutional challenges-To implement wide scale mobile learning management needs to define clear policy and technical and pedagogical support. It is important institutions to adopt mobile learning strategy.

Design challenges-Understanding the capabilities of mobile devices equipped with cameras, sensors, Internet access and additional software will help designers to explore potential of mobile learning. Poorly designed mobile technologies adversely affect usability and can distract children from learning goals. Physical aspects of mobile technologies that may prevent an optimal learning experience include restricted text entry, small screen size, and limited battery life [7].

Technical challenges-Technical challenges are related to the infrastructure, security, technical support and maintenance, reliability, wide range of form factors and equipment with sensors and additional devices or additional software.

Evaluation challenges-Currently, no widely accepted learning theory for mobile technologies has been established, hampering the effective assessment, pedagogy, and design of new applications for learning [7].

Cultural and social challenges-Though many experts believe that mobile devices have significant potential to transform children's learning, parents and teachers apparently are not yet convinced. Still most teachers see smartphones as distractions. Cultural differences in relation to perceptions and attitudes toward technology are key factors for both the acceptance of these types of technology and for their future use. Introducing $\mathrm{m}$-learning to a new culture brings many issues that need to be investigated. It is very important first to understand the nature of the target culture and to use the findings as a basis for m-learning project implementation [7].

\section{Design of the Empirical Study}

In line with research findings, the focus of the study is related to the opportunities for smart devices use in school education, outlining the main obstacles and challenges to it. The subject of research is students' interest in the use of multimedia educational devices for educational purposes. The aim of the study is to establish the main determinants for the complete and purposeful application of the smart devices in the school education. The empirical study was conducted between April and June 2018 as a research contingent of 190 pupils aged between 14 and 18 trained in lower and upper secondary schools. The survey was conducted through an online questionnaire comprising 17 items, two of which relate to the learner's status. The main group of questions are in the following main directions:

- Installed apps on students' devices;

- Usage of WiFi and mobile data to connect the Internet;

- Accessed educational applications and frequency of use;

- Preferences for application functionalities;

- Role of the teacher for systematic and purposeful use of smart devices in educational scenarios. 


\section{$4 \quad$ Results}

Within the research, students' preference for the smartphone as a multimedia device is clearly demonstrated. For $72.1 \%$, it is the most preferable device compared to personal computer $(20.5 \%)$, game console $(4.7 \%)$ or e-book $(2.6 \%)$. There were no students who have listed tablets as the most preferred device. This is most likely due to the fact that, despite overlapping its basic functionality with smartphones, its size influences the student's preference for their daily use. With such a high level of preference of smart-devices, it is essential to look for opportunities for their use for educational purposes, even though there are tendencies to completely ban them in school.

$76.8 \%$ of the respondents use mobile data in school, and $53.2 \%$ of them are WiFi connected. Unfortunately, only $9 \%$ of pupils use educational applications at least once a day. $19 \%$ of them use the network very rarely for this purpose and $46 \%$ only when it is needed or necessary. I.e. despite the availability of WiFi and mobile data connectivity at school, only $9.4 \%$ of students use available educational applications at least once a week. The same tendency is observed outside school as well.

$67.4 \%$ of the students use the standard applications on their smartphone, such as calculators. $33.7 \%$ of the respondents have applications for learning a foreign language, although there is no statistically significant link between the preferred language setting of the phone interface and the knowledge of a foreign language. In less than $30 \%$ of the cases, it matters. $23.7 \%$ of students have apps for training on observation and thinking, $13.2 \%$ of them use apps for music lessons, and only $11 \%$ of the students use video tutorials on specific subjects. This is most likely due to the fact that more than $50 \%$ of students explicitly claim that their teachers are failing to successfully integrate smartphone capabilities in the learning process. Only $10 \%$ of the respondents provide a sufficient set of cognitive situations involving the use of smartphones by the students.

For $24.7 \%$ of the students, the main disincentive for using an application for educational purposes is the poor organization of its interface. $22.1 \%$ of the respondents are dissatisfied with the functionalities of the applications they use and $21 \%$ of them are dissatisfied because of the lack of the information that apps contain or provide. $19 \%$ of the respondents think that there is a significant discrepancy between the content and the pace of learning at school and learning within the educational applications. This lack of synchronization, coupled with inadequate interest and purposefulness on the part of teachers, demotivates students and discourages them from using smart educational devices. This fact deserves special attention and represents a research interest in the future.

$61.6 \%$ of students strongly believe that the smartphone provides quick and easy access to learning content, and if it is structured appropriately and in accordance with the requirements, it will facilitate the process of learning it and motivate them to use their smartphones purposefully in undergoing training. Although not a small percentage of students- $67.8 \%$, often use their smartphone to help solve their own homework, these resources are still not fully utilized to their full degree in school settings.

For $57.9 \%$ of the respondents, the presence of gamification elements in educational applications is crucial for their use, and for $51 \%$ of them the presence of the so-called "social elements" or the ability to create communities and ensure publicity of results in 
the educational process is crucial. $95 \%$ of the students share the applications they use for educational purposes, but unfortunately only $12 \%$ of them share with their teachers and seek their support for their goal-oriented use in learning.

All this draws the attention of educational professionals to seeking optimal use of smart devices in the learning process without a total rejection or overestimation of their capacities in order to ensure commitment to the educational target (to those over $80 \%$ of students) that use mobile data and WiFi connectivity in school. Smart devices are important and desired to students in their daily activities. The total ban on using smart devices for $25 \%$ of students is perceived as a very severe punishment and $43 \%$ of them as a moderate one. This once again highlights the importance of smart devices for students and their presence in their daily activities.

\section{Conclusion}

Within the conducted research, the results clearly show that the realization of mobile learning as a model of mixed or distance learning that meets the needs of the trainees as an educational model independent of time and place is most appropriately carried out through smart devices. This makes it possible for students to use mobile learning spontaneously, to determine it personally, and benefit from it in a connected (shared) and partly informal manner. Thus, the learner has their own responsibility in learning, and realizes their own pace of learning according to their own style, which takes place in the context of a full co-operation and an opportunity for continuous self-evaluation.

The mobile environment, according to the respondents, should ensure positive transitions and, facilitating interaction, must revive their interest and motivation for learning.

\section{References}

[1] Kim, H. \& Kwon, Y. (2012). Exploring smartphone applications for effective mobile-assisted language learning. Multimedia-Assisted Language Learning, 15(1): 31-57

[2] Levunlieva, M. (2015). From perception through understanding to creative imagination. Knowledge, 10(1): 100-104.

[3] Buhcheva, T. (2016). Digital technology and the training of digital youth. Pedagogical Innovations (In Bulgarian)

[4] El-Hussein, M. O. M., \& Cronje, J. C. (2010). Defining mobile learning in the higher education landscape. Educational. Technology \& Society, 13(3): 12-21

[5] Sharples, M., Taylor, J., \& Vavoula, G. (2005). Towards a theory of mobile learning. In H. van der Merwe \& T. Brown (Eds.) Mobile technology: The future of learning in your hands, mLearn 2005, Book of Abstracts: p. 58

[6] Shuler, C. (2009). Pockets of potential: Using mobile technologies to promote children's learning. New York, NY: The Joan Ganz Cooney Center at Sesame Workshop

[7] Cheon, J., Lee, S., Crooks, S. M. \& Song, J. (2012). An investigation of mobile learning readiness in higher education based on the theory of planned behavior, Computers \& Education, 59 (3): 1054-1064, https://doi.org/10.1016/j.compedu.2012.04.015 
[8] Rasheva-Merdjanova, Y. (2017). Synergy Philosophy of Education. Sinergy Natural Education. Synergy Education. University Press "St. Kliment Ohridski", Sofia (In Bulgarian)

[9] Georgieva-Lazarova, St. \& Lazarov, L. (2017). 21st Century Pedagogy. University Press "St. Cyril and St. Methodius": Veliko Tarnovo (In Bulgarian)

[10] Georgieva-Lazarova, St. (2012). Training in Digital Environment. University Press "St. Cyril and St. Methodius": Veliko Tarnovo (In Bulgarian)

[11] Rasheva-Merdjanova, Y. (2005). The multisensory principle in learning and in life. University Press "St. Kliment Ohridski", Sofia (In Bulgarian)

[12] Al-Hunaiyyan, A., Alhajri, R. A., \& Al-Sharhan, S. (2016). Perceptions and challenges of mobile learning in Kuwait. Journal of King Saud University-Computer and Infor-mation Sciences, 30 (2): 279-289, https://doi.org/10.1016/i.jksuci.2016.12.001

\section{$7 \quad$ Authors}

Ivo Damyanov has a master's degree in Mathematics and he holds a doctor's degree in Computer science. He is an assistant professor at the Department of Informatics. His professional and scientific research interests are in the fields of: metaprogramming, domain-specific languages and code generation, discrete functions, e-learning and distance learning.

Nikolay Tsankov has a master's degree in Theory and methodology of teaching chemistry and physics and he holds a doctor's degree in Education. His professional and scientific research interests are in the fields of: theories of instruction, school didactics, theories of education, information theories in education, cognitive modelling in education, competence-based approach in education, competence for modelling, motivation in education, audio-visual and information technologies in education.

Article submitted 06 October 2018. Final acceptance 30 October 2018. Final version published as submitted by the authors. 